\title{
KESIAPAN PELAKSANAAN PRAKTIK KERJA INDUSTRI PROGRAM STUDI KEAHLIAN TEKNIK BANGUNAN DI KOTA MAKASSAR
}

\author{
Anas Arfandi dan Onesimus Sampebua \\ Fakultas Teknik Universitas Negeri Makasar \\ Email: anas_arfandi@yahoo.com
}

\begin{abstract}
Abstrak: Penelitian bertujuan untuk mendeskripsikan kesiapan siswa SMK dan sekolah menghadapi praktik kerja industri dan kesiapan pihak industri melaksanakan praktik kerja industri. Penelitian ini termasuk jenis survei. Populasi penelitian adalah seluruh guru pembimbing prakerin dan kepala sekolah, instruktur prakerin di industri, dan seluruh siswa kelas XI program keahlian teknik bangunan di Kota Makassar yang telah melaksanakan prakerin. Penarikan sampel menggunakan ProportionateSampling. Teknik pengumpulan data dilakukan dengan angket, pengamatan, dan dokumentasi, sedang analisis data dengan teknik statistik deskriptif. Hasil penelitian menunjukkan bahwa siswa SMK siap melakukan praktik kerja industri. Hal itu didukung oleh tingkat pengetahuan siswa, sosialisasi yang dilakukan oleh sekolah, dan kemampuan keterampilan dasar siswa yang baik. SMK siap melakukan praktik kerja industri. Industri pelaksana prakerin siap melakukan praktik kerja industri terutama pada industri golongan besar dan menengah, sedang industri golongan kecil hanya $75 \%$. Kerja sama yang terbangun antara industri dan sekolah masih kurang baik terutama pada industri-industri golongan kecil, sedang golongan menengah dan besar sudah cukup baik walaupun masih sangat terbatas.
\end{abstract}

Kata kunci: kesiapan, praktik kerja industri, program studi keahlian teknik bangunan

\section{THE READINESS IN IMPLEMENTING THE INDUSTRIAL WORK EXPERIENCE PROGRAM OF THE VOCATIONAL HIGH SCHOOL CIVIL ENGINEERING DEPARTMENT IN MAKASSAR CITY}

\begin{abstract}
This study was aimed to describe the readiness of the vocational high school students, the schools and the industries to implement the industrial work experience program. This study belongs to a survey method. The population consisted of all teachers supervising the industrial work experience program and principals, all instructors in industries, and all grade XI students in the civil engineering program in Makassar City joining the industrial work experience program. The sample was drawn using the proportional stratified sampling technique. The data were collected using questionnaires, observations, and documentation, while the data were analyzed descriptively. The findings showed that the students were ready to implement the industrial work experience program. This was supported by the students' knowledge level, the socialization done by the schools, and the students' good basic skill ability. The vocational high schools were ready to implement the industrial work experience program. The industries were also ready to implement the industrial work experience program, especially those belonging to the large and medium scales, while the small scale industries were not fully ready (only $75 \%$ ). The cooperation between industries and schools were not good, especially in the small scale industries, while in the large and medium scale industries, the cooperation was better, though it was still limited.
\end{abstract}

Keyword: the readiness, industrial work experience program, civil engineering

\section{PENDAHULUAN}

Kemajuan teknologi dan dinamika tempat kerja serta tantangan di dunia kerja yang menuntut kompetensi kerja yang tinggi, mengharuskan institusi pendidikan kejuruan untuk mengantisipasi dan menghadapi perubahan tersebut dengan menyiapkan lulusan yang mampu mengoptimalkan potensi dirinya untuk memiliki kompetensi 
yang diharapkan dunia kerja. Selain itu, institusi pendidikan vokasi juga harus mengembangkan kapasitas kerjasama dengan lembaga mitra kerjasama untuk memberikan pengalaman belajar di dunia kerja nyata.

Salah satu karakteristik pendidikan kejuruan adalah mempersiapkan peserta didik untuk memasuki lapangan kerja, sehingga seharusnya pendidikan kejuruan didasarkan atas "demand driven" yakni kebutuhan akan dunia kerja (Wardiman, 1998). Program pendidikan berbasis ganda dengan pendekatan link and match, mengharapkan agar pendidikan kejuruan itu dilaksanakan di dua tempat. Salah satu konsep pelaksanaan pendidikan berbasis ganda adalah sistem magang bagi siswa SMK yang lebih dikenal dengan Praktik Kerja Industri (Prakerin).

Prakerin marupakan salah satu strategi pembelajaran dalam penyelenggaraan pendidikan kejuruan masih terus dilakukan pengembangan agar kualitas lulusannya dapat sesuai tuntutan pasar kerja. Pembelajaran tersebut sejatinya dilakukan dengan mendekatkan pembelajaran dengan dunia kerja yang disebut sebagai pembelajaran berbasis kerja atau Work-Based Learning (WBL). Pembelajaran ini menjadi salah satu pilihan yang tepat walaupun masih terus dilakukan perbaikan yang disesuaikan dengan kondisi daerah setempat.

Pembelajaran berbasis kompetensi yang dilakukan di SMK Pardjono \& Hestina (2012) menggunakan pendekatan behavioristik, kognitivistik, konstruktivistik, dan representasinya pada penggunaan motivasi, media, dan metode yang sesuai karakteristik peserta didik untuk mengoptimalkan kepekaan sensori peserta didik; dan (2) strategi belajar aktif pada umumya dilaksanakan dengan prinsip konstruktivistik.

Boud \& Solomon (2001) menyatakan bahwa WBL merupakan suatu upaya pengembangan karir secara kontinyu dengan menjalin kemitraan antara lembaga pendidikan dengan dunia kerja. Dalam hal ini, lembaga pendidikan dan dunia usaha/industri secara bersama-sama merancang pembelajaran di tempat kerja, sehingga program ini memenuhi kebutuhan peserta didik dan berkontribusi dalam pengembangan perusahaan.

Metode WBL merupakan terminologi yang digunakan kepada siswa agar mereka mendapat- kan pengalaman melalui bekerja. Hal ini berguna untuk mengadaptasi siswa sebagai proses transisi sebelum bekerja dan membuka cakrawala mereka mengenai lingkungan keja nyata dan memungkinkan mereka untuk memilih karir yang tepat (Fleming \& Martin, 2007).

Joseph (2008) menjelaskan bahwa WBL merupakan pengalaman belajar yang berisi berbagai pengalaman dan menjadi pengetahuan konseptual. Lebih lanjut diungkapkan bahwa di dalam pembelajaran berbasis kerja, teori kemungkinan dapat diperoleh pada saat praktik. Lebih lanjut Widarto, dkk (2012) mengungkapkan bahwa salah satu model pendidikan hard skill bagi siswa terutama siswa SMK dapat dilakukan di dudi melalui prakerin dan teaching industry.

Becker (2007) menjelaskan bahwa WBL merupakan pendekatan pembelajaran yang diarahkan pada pengalaman bekerja dimana siswa harus melalui proses pembelajaran pada suatu lembaga untuk mendapatkan pengalaman dan menerapkan keterampilan yang dimiliki pada industri yang terkait dengan lingkungan kerja nyata nantinya.

Empat konsep yang merupakan bagian utama dari pelaksanaan praktik kerja industri menurut Reeve \& Gallacher (2005), adalah: 1) kemitraan, 2) fleksibilitas, 3) relevansi, dan 4) akreditasi. Pelaksanaan prakerin tidak hanya menempatkan siswa di industri dan mendapatkan pengalaman bekerja, akan tetapi sekolah diharapkan dapat menyediakan kebutuhan industri akan sumber daya yang memiliki keterampilan dasar pekerjaan. Modal inilah yang selanjutnya menjadi modal awal bagi siswa yang akan melaksanakan prakerin agar dapat dilibatkan dalam pengalaman kerja yang lebih luas dan berinteraksi dengan karyawan lainnya. Untuk itu kemitraan sekolah dan industri seharusnya mencakup kemampuan siswa untuk dapat bekerja dan membantu perusahaan dalam meningkatkan produksinya.

Tenaga kerja yang sesuai dengan kebutuhan DUDI merupakan tantangan pendidikan kejuruan. Hal ini telah diungkapkan oleh Wardiman (1998) bahwa salah satu karakteristik pendidikan kejuruan adalah mempersiapkan peserta didik untuk memasuki lapangan kerja, sehingga seharusnya pendidikan kejuruan didasarkan atas "demand driven" yakni permintaan dunia kerja. 
Namun demikian, kenyataan di lapangan sebagaimana dikemukakan Slamet (2013) bahwa praktik penyelenggaraan SMK di Indonesia saat ini menunjukkan kelemahan-kelemahan sebagai berikut: menyelenggarakan fungsi tunggal, yaitu menyiapkan siswa untuk bekerja, menjadi karyawan, dan kurang menyiapkan untuk menjadi wirausahawan, kurang cepat tanggap terhadap tuntutan-tuntutan pembangunan ekonomi, lemah keselarasannya dengan dunia kerja, dan tidak ada jaminan untuk memperoleh pekerjaan yang layak. Karena itu, untuk memainkan peran yang lebih luas SMK diharapkan dapat memperluas fungsinya dari fungsi tunggal menjadi SMK Model yang menyelenggarakan fungsi majemuk yang selaras dengan kemajemukan kebutuhan masyarakat.

\section{METODE}

Penelitian ini merupakan penelitian survei. Populasi dalam penelitian adalah seluruh guru pembimbing prakerin dan kepala sekolah, instruktur prakerin di industri, dan seluruh siswa kelas III program keahlian Teknik Bangunan SMK Negeri di Kota Makassar. Penarikan sampel menggunakan Proportionate Sampling.

Pengumpulan data menggunakan metode angket, observasi, dan dokumentasi. Angket yang digunakan disusun dalam rangka mengungkap berbagai hal yang telah dilakukan oleh responden dan kondisi yang terjadi pada saat ini. Tanggapan responden yang ingin diungkapkan terkait dengan kesiapan siswa, sekolah, dan industri dalam melaksanakan prakerin. Metode dokumentasi digunakan untuk menjaring data tentang dokumen kerjasama dan hasil pelaksanaan prakerin sebelumnya. Analisis data dilakukan dengan teknik statistik deskriptif.

\section{HASIL DAN PEMBAHASAN \\ Kesiapan Siswa}

Penelitian yang telah dilakukan menunjukkan bahwa siswa yang akan melakukan prakerin dapat dikategorikan memiliki kesiapan yang baik. Deskripsi data hasil penelitian menunjukkan $36,67 \%$ menyatakan sangat siap, $58,89 \%$ menyatakan siap, dan hanya $4,44 \%$ yang menyatakan kurang siap. Hal tersebut selengkapnya ditunjukkan pada Tabel 1.
Tabel 1. Kategori Jawaban Kesiapan Siswa

\begin{tabular}{|c|c|c|c|c|c|}
\hline Kategori & \multicolumn{3}{|c|}{ Rentang Skor } & $\mathrm{F}$ & $\%$ \\
\hline Sangat tidak siap & & $\leq$ & 64.00 & 0 & 0.00 \\
\hline Tidak siap & 64.01 & - & 85.33 & 0 & 0.00 \\
\hline Kurang siap & 85.34 & - & 106.67 & 4 & 4.44 \\
\hline Siap & 106.68 & - & 128.00 & 53 & 58.89 \\
\hline Sangat siap & & $>$ & 128.00 & 33 & 36.67 \\
\hline Total & & & & 90 & 100.00 \\
\hline
\end{tabular}

Kesiapan yang baik dari siswa sebelum melakukan prakerin sangat diperlukan. Hal ini tentunya akan berdampak pada aktifitas prakerin yang dapat berjalan dengan baik dan mendapatkan hasil sesuai harapan dari prakerin berupa pengalaman kerja kepada siswa. Hasil evaluasi yang telah dilakukan menunjukkan bahwa siswa siap melakukan prakerin. Kesiapan siswa terlihat dari pengetahuan siswa mengenai prakerin, sosialisasi yang sangat intens yang dilakukan oleh sekolah dan motivasi siswa untuk mencari tahu segala informasi mengenai prakerin juga menjadi pendukung tingkat kesiapan siswa dalam melaksanakan prakerin. Kemampuan dasar siswa dalam beradaptasi dengan lingkungan dan budaya kerja industri, 56,67\% siswa menyatakan mampu untuk melaksanakan prakerin bahkan $24,44 \%$ menyatakan sangat mampu. Namun ada juga 17,78\% siswa yang merasa memiliki kemampuan kurang mampu bahkan $1,11 \%$ merasa tidak mampu.

\section{Kesiapan Sekolah}

Hasil penelitian memperlihatkan bahwa pihak sekolah dapat dikategorikan memiliki kesiapan yang sangat baik. Deskripsi data hasil penelitian menunjukkan $64,29 \%$ menyatakan sangat siap, dan 35,71\% menyatakan siap. Keadaan tersebut selengkapnya dapat ditunjukkan pada Tabel 2.

Tabel 2. Kategori Jawaban Kesiapan Sekolah

\begin{tabular}{|c|c|c|c|c|c|}
\hline Kategori & \multicolumn{3}{|c|}{ Rentang Skor } & $\mathrm{F}$ & $\%$ \\
\hline Sangat tidak siap & & $\leq$ & 102.00 & 0 & 0.00 \\
\hline Tidak siap & 102.01 & - & 136.00 & 0 & 0.00 \\
\hline Kurang siap & 136.01 & - & 170.00 & 0 & 0.00 \\
\hline Siap & 170.01 & - & 204.00 & 5 & 35.71 \\
\hline Sangat siap & & $>$ & 204.00 & 9 & 64.29 \\
\hline Total & & & & 15 & 100.00 \\
\hline
\end{tabular}


Kesiapan sekolah terlihat dari sumber daya manusia yang dimiliki terutama pada ketersediaan guru pembimbing yang berpengalaman, fasilitas pendidikan yang baik dalam mendukung prakerin, administrasi pendidikan yang tertata baik, perencanaan pembiayaan prakerin yang matang, dan kerjasama dengan industri pasangan yang terbangun dengan baik. Dari hasil evaluasi dapat dikatakan bahwa sekolah sangat siap melaksanakan prakerin.

Kesiapan sekolah tergambar dari aspek pengetahuan mengenai prakerin, sosialisasi yang dilakukan baik informasi yang berasal dari kementerian pendidikan, maupun informasi dari dinas pendidikan setempat. Hanya saja, tingkat kerjasama sekolah dengan industri mitra pelaksana prakerin masih pada tingkat baik sebesar 57,14\%, tingkat sangat baik sebesar $35,71 \%$, namun ada juga yang berpendapat bahwa kerjasama sekolah dan industri masih kurang yakni sebesar 7,14\%. Guru pembimbing merupakan orang-orang yang telah berpengalaman dalam membimbing siswa prakerin, pembiayaan prakerin masih dibebankan kepada siswa yang akan melaksanakan prakerin tanpa ada subsidi dari pihak sekolah, komite sekolah, dan industri. walaupun demikian, administrasi prakerin disekolah menunjukkan bahwa semua sekolah melaksanakan pengarsipan persuratan dengan sangat baik.

\section{Kesiapan Industri}

Industri pasangan prakerin dapat dikategorikan memiliki kesiapan yang baik. Tingkat kategori kesiapan industri secara keseluruhan mencapai $75,00 \%$ siap hanya $25,00 \%$ yang kurang siap. Untuk lebih jelasnya tentang keadaan tersebut dirunjukkan pada Tabel 3 .

Tabel 3. Kategori Jawaban Kesiapan Industri

\begin{tabular}{|c|c|c|c|c|c|}
\hline \multirow{2}{*}{$\begin{array}{l}\text { Kategori } \\
\text { Sangat tidak siap }\end{array}$} & \multicolumn{3}{|c|}{ Rentang Skor } & \multirow{2}{*}{$\frac{F}{0}$} & \multirow{2}{*}{$\frac{\%}{0.00}$} \\
\hline & & $\leq$ & 82.00 & & \\
\hline Tidak siap & 82.01 & - & 109.33 & 0 & 0.00 \\
\hline Kurang siap & 109.34 & - & 136.67 & 4 & 25.00 \\
\hline Siap & 136.68 & - & 164.00 & 12 & 75.00 \\
\hline Sangat siap & & $>$ & 164.00 & 0 & 0.00 \\
\hline Total & & & & 16 & 100.00 \\
\hline
\end{tabular}

Dari penelitian yang dilakukan, diperoleh data bahwa industri yang kurang siap melaksana- kan prakerin berasal dari industri swasta dengan golongan kecil yang bergerak dalam bidang konsultan dan kontraktor. Sementara industri yang menyatakan siap melaksanakan prakerin berasal dari industri BUMN dan industri swasta. Kesiapan industri melaksanakan prakerin didukung dengan jawaban $50,00 \%$ responden yang menyatakan mengetahui maksud, tujuan, manfaat, dan harapan dari pelaksanaan prakerin. Selanjutnya, 50,00\% responden menyatakan kurang tahu maksud, tujuan, manfaat, dan harapan dari pelaksanaan prakerin. Walaupun demikian 56,25\% pihak industri masih menyatakan bahwa kerjasama industri dengan sekolah hanya cukup baik, bahkan $12,50 \%$ responden berpendapat kurang baik.

Instruktur prakerin merupakan instruktur yang dapat membimbing siswa dalam prakerin dengan $81,25 \%$ jawaban responden yang menyatakan sangat setuju. Hal ini didukung oleh pengalaman instruktur dalam bidang pekerjaannya serta pengalaman 5 - 10 tahun dalam pembimbingan siswa prakerin. Selain itu, instruktur prakerin juga dilibatkan dalam kegiatan-kegiatan yang dilakukan oleh pihak sekolah, baik sekolah mitra pelaksanaan prakerin maupun sekolah lainnya.

Grafik kesiapan industri berdasarkan golongan industri disajikan pada Gambar 1.

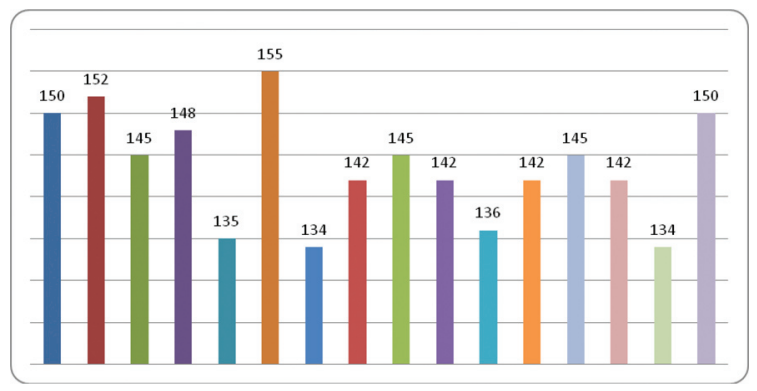

\section{Gambar 1. Skor Kesiapan Industri Berdasarkan Bidang Pekerjaan}

Gambar 1 memperlihatkan bahwa dari 16 industri yang menjadi sampel penelitian, terdapat 7 perusahaan konsultan yang menjadi responden, 7 perusahaan kontraktor, dan 2 perusahaan developer. Skor yang dicapai masing-masing bidang keahlian perusahaan cukup bervariasi. Hal ini menunjukkan bahwa setiap perusahaan memiliki kesiapan yang berbeda dalam melaksanakan praktik industri. 


\section{Pembahasan \\ Kesiapan Siswa}

Siswa diharapkan memiliki kesiapan yang baik sebelum melakukan prakerin sehingga dapat beraktifitas dengan baik pada saat pelaksanaan prakerin dan mendapatkan hasil sesuai harapan dari prakerin berupa pengalaman kerja kepada siswa. Selain itu, kesiapan siswa yang baik diharapkan mampu memberikan kelulusan $100 \%$ kepada siswa dan mendapatkan sertifikat prakerin.

Berdasarkan hasil evaluasi yang telah dilakukan, dapat dikatakan bahwa siswa siap melaksanakan prakerin. Hal ini didukung oleh tingkat pengetahuan siswa mengenai prakerin yang sangat tahu sebesar $57,78 \%$, yang tahu sebesar $36,67 \%$, dan hanya $5,56 \%$ yang kurang mengetahui tentang prakerin. Sosialisasi yang sangat intens yang dilakukan oleh sekolah dan motivasi siswa untuk mencari tahu segala informasi mengenai prakerin juga menjadi pendukung tingkat kesiapan siswa dalam melaksanakan prakerin. Dari aspek sosialisasi, terdapat lebih dari $80 \%$ siswa yang menyatakan bahwa sosialisasi yang telah dilakukan oleh sekolah. Kemampuan dasar siswa dalam beradaptasi dengan lingkungan dan budaya kerja industri, terlihat baik yang ditunjukkan pada perolehan data yang mencapai lebih dari sepertiga responden.

Rhodes \& Shiel (2007) menekankan perlunya peserta didik mempersiapkan dirinya untuk melaksanakan prakerin melalui peningkatan pemahaman lingkungan kerja, pemahaman bidang ilmu, dan keterampilan menggunakan peralatan yang ada di industri. Kesiapan siswa dalam pelaksanaan praktik industri yang terlihat baik harus ditingkatkan secara simultan karena berbagai tuntutan masa depan yang tidak tidak hanya menuntut kesiapan kerja, tetapi juga kesiapan dalam meningkatkan pertumbuhan ekonomi Indonesia yang ada di dalam master plan percepatan pembangunan ekonomi Indonesia (MP3EI), kemajuan teknologi yang sangat pesat, dan tuntutan globalisasi yang tidak mengenal batas-batas wilayah (Slamet, 2013).

\section{Kesiapan Sekolah}

Sekolah diharapkan memiliki sumber daya manusia yang memadai terutama guru pembim- bing yang berpengalaman dalam prakerin, memiliki fasilitas pendidikan yang baik terutama yang mendukung prakerin, administrasi pendidikan yang tertata dengan baik, perencanaan pembiayaan prakerin yang baik, dan kerjasama yang baik dengan industri pasangan.

Hasil deskripsi data penelitian evaluasi memperlihatkan bahwa pihak sekolah dapat dikategorikan memiliki kesiapan yang sangat baik. Hal ini didukung pengetahuan sekolah dalam melaksanakan prakerin selama puluhan tahun sejak pemberlakuan pendidikan sistim ganda (PSG) pada tahun 1997. Selain itu, sosialisasi yang sering dilakukan baik informasi dari pusat, maupun informasi dari dinas pendidikan setempat memberikan dampak yang positif dalam pelaksanaan prakerin. Hanya saja, dari \pm 12 tahun melaksanakan prakerin, tingkat kerjasama sekolah dengan industri mitra pelaksana prakerin dapat dikatakan baik yang mencapai lebih dari 90\% responden, walaupun masih terdapat $7,14 \%$ yang berpendapat hanya cukup baik.

Guru pembimbing merupakan orang-orang yang telah berpengalaman dalam mendampingi siswa prakerin serta telah memiliki pemahaman yang sangat baik mengenai dunia industri sehingga hal ini juga menjadi pendukung tingkat kesiapan sekolah yang sangat baik. Hanya saja, dalam hal pembiayaan prakerin masih dibebankan kepada siswa yang akan melaksanakan prakerin tanpa ada subsidi dari pihak sekolah, komite sekolah, dan industri.

Berdasarkan hasil observasi dan wawancara yang dilakukan mengenai administrasi prakerin disekolah menunjukkan bahwa semua sekolah melaksanakan pengarsipan persuratan dengan sangat baik. Penataan ruang kerja hubungan industri serta penataan surat-surat dan arsip juga menjadi faktor penentu kesiapan sekolah melaksanakan prakerin. Daftar industri mitra pelaksana prakerin dari tahun ke tahun sebagai dasar dalam melakukan prakerin selanjutnya tersimpan dengan baik bahkan dibuat dalam bentuk papan informasi.

Kerjasama industi dan sekolah ini didukung dengan adanya dokumen kerja sama dalam bentuk Memorandum of Understanding (MoU) antara pihak sekolah dan industri, walaupun bentuk kerjasama ini hanya dilakukan oleh SMK Negeri 
5 Makassar, sementara SMK Negeri 2 dan SMK Negeri 3 belum melakukan hal tersebut secara tertulis dan berkelanjutan. Sarana dan prasarana sekolah terutama yang mendukung pelaksanaan prakerin dalam kondisi yang baik, seperti: ruang kelas, bengkel kerja, laboratorium komputer, dan sarana pendukung lainnya.

Walaupun kesiapan sekolah dalam pelaksanaan praktik industri sudah sangat baik, namun dalam menghadapi tuntutan masa depan SMK sudah harus dirancang menjadi SMK Model dengan menyelenggarakan fungsi majemuk berdasarkan kemajemukan kebutuhan masyarakat, khususnya dunia kerja. Keselarasannya dengan kebutuhan masyarakat merupakan imperatif, baik dalam dimensi kuantitas, kualitas, lokasi, maupun waktu. Transisi menuju SMK Model memerlukan penataan ulang kebijakan, perencanaan, penganggaran, kelembagaan, dan sumber daya yang diperlukan untuk menyelenggarakan SMK Model (Slamet, 2013).

Pentingnya sekolah mempersiapkan pelaksanaan prakerin sejalan dengan temuan Rhodes \& Shiel (2007) yang menjelaskan bahwa pelaksanaan WBL mengalami resonansi yang cukup luas. Beberapa hal yang menjadi temuan mereka adalah: Pelaksanaan WBL perlu memperhatikan kesiapan peserta didik dan sekolah dalam hal menyiapkan peserta didik dalam memahami lingkungan kerja tempat pelaksanaan prakerin terutama dalam hal pemahaman bidang ilmu, dan keterampilan menggunakan peralatan; peningkatan kemampuan secara bertahap sangat diperlukan mengingat keberagaman kemampuan kognisi dan kebutuhan belajar peserta didik; serta berbagai kegiatan pembelajaran dan cara penilaian bagi peserta didik yang melakukan WBL.

\section{Kesiapan Industri}

Industri pasangan idealnya memiliki pengetahuan prakerin yang baik, instruktur prakerin yang berpengalaman dalam membimbing, aspek produksi yang berkelanjutan, dan memiliki ikatan kerjasama dengan sekolah menengah kejuruan untuk menjadi industri pasangan pelaksanaan prakerin.

Berdasarkan hasil evaluasi, industri mitra prakerin dapat dikategorikan memiliki kesiapan yang baik. Industri yang kurang siap berasal dari industri swasta dengan golongan kecil yang bergerak dalam bidang konsultan dan kontraktor. Sementara industri yang menyatakan siap melaksanakan prakerin berasal dari industri BUMN dan industri swasta yang masuk pada golongan industri besar.

Sarana dan prasarana yang memadai yang dimiliki oleh industri, serta manajemen yang baik sangat membantu siswa dalam melaksanakan prakerin secara terstruktur dan memenuhi kebutuhan siswa dalam memiliki pengalaman belajar yang nyata. Selain itu, sumber daya manusia yang handal dalam mengelola perusahaan sehingga siswa-siswa yang melaksanakan prakerin dapat memperoleh pengetahuan dan pengalaman dari instruktur pembimbing industri dan karyawan lainnya yang menjadi mitra kerja para siswa.

Kesiapan industri melaksanakan prakerin juga didukung dengan jawaban separuh responden yang menyatakan mengetahui maksud, tujuan, manfaat, dan harapan dari pelaksanaan prakerin. Industri ini terbagi atas industri BUMN sebanyak 2 buah bergerak dalam bidang kontraktor dan bidang pabrikasi dengan golongan besar, industri swasta sebanyak 10 buah yang terdiri dari 2 golongan besar bergerak dalam bidang konsultan dan developer, 4 golongan menengah bergerak dalam bidang konsultan dan kontraktor, dan 4 golongan kecil bergerak dalam bidang konsultan dan developer, sedangkan $18,75 \%$ responden menyatakan kurang tahu maksud, tujuan, manfaat, dan harapan dari pelaksanaan prakerin. Industri yang menjawab kurang tahu mengenai prakerin berasal dari industri swasta golongan kecil yang bergerak dalam bidang konsultan 1 buah dan bidang kontraktor 3 buah.

Walaupun demikian, 56,25\% pihak industri masih menyatakan bahwa kerjasama industri dengan sekolah masih kurang baik. Pernyataan ini berasal dari industri swasta yang bergerak dalam bidang konsultan dan kontraktor. Konsultan yang menyatakan kurang baik terdiri dari 1 golongan menengah dan 4 dari golongan kecil, sementara kontraktor yang menyatakan kurang baik terdiri dari 2 golongan menengah dan 3 dari golongan kecil. Sedangkan $31,25 \%$ industri menyatakan baik yang berasal dari industri BUMN yang bergerak dalam bidang kontraktor dan bidang konsultan, sementara industri swasta terdiri dari 2 golongan 
besar yang bergerak dalam bidang konsultan dan kontraktor, dan golongan menengah yang bergerak dalam bidang konsultan.

Instruktur prakerin merupakan instruktur yang dapat membimbing siswa dalam prakerin dengan $81,25 \%$ jawaban responden yang menyatakan sangat setuju. Hal ini didukung oleh pengalaman instruktur dalam bidang pekerjaannya serta pengalaman dalam pembimbingan siswa prakerin sekitar 5-10 tahun. Selain itu, instruktur prakerin juga dilibatkan dalam kegiatan-kegiatan yang dilakukan oleh pihak sekolah, baik sekolah mitra pelaksanaan prakerin maupun sekolah lainnya.

Pembiayaan prakerin terutama ketika siswa telah berada di industri merupakan tanggung jawab sepenuhnya dari pihak industri. Namun masih terdapat industri yang kurang setuju pembiayaan prakerin dibebankan kepada industri. Pendapat ini berasal dari industri swasta golongan kecil yang bergerak dalam bidang konsultan dan kontraktor. Industri yang setuju berasal dari industri BUMN dan industri swasta. Industri BUMN dengan golongan besar bergerak dalam bidang pabrikasi, sementara industri swasta terdiri dari 1 konsultan golongan besar, 2 konsultan golongan menengah, 2 kontraktor golongan menengah, 3 konsultan golongan kecil, 2 kontraktor golongan kecil dan 1 buah developer golongan kecil. Industri yang sangat setuju dengan pernyataan pembiayaan prakerin merupakan industri BUMN 1 buah yang bergerak dalam bidang kontraktor dengan golongan besar, dan 1 buah industri swasta yang bergerak dalam bidang developer dengan golongan besar.

Sebagaimana disimpulkan oleh Syamhanim et al (2015) bahwa dari lima model WBL yang dibahas: WBL-Arizona Work-Based Learning Resource Guide Model; WBL Model in Malaysia from the Automotive Diploma program and the collaboration between the Community College and Proton; The Technical InstitutionIndustry Connection Model; Edmunds' Model; dan the WBL Model based on the involvement zone of the student, educational institution and industry, ditemukan bahwa semua model tersebut menekankan bahwa metode WBL membutuhkan keterlibatan siswa, lembaga pendidikan dan majikan industri. Dengan kata lain bahwa kesiapan seluruh pihak yang terkait sangat diperlukan dalam rangka pencapaian hasil yang maksimal dari program WBL terutama pada peningkatan nilai tambah siswa yang akan unggul dalam teori, akademik, dan keterampilan teknis.

\section{SIMPULAN}

Berdasarkan hasil penelitian yang dilakukan tentang kesiapan pelaksanaan praktik kerja industri program keahlian teknik bangunan, dapat disimpulkan hal-hal sebagai berikut.

1. Siswa SMK program keahlian Teknik Bangunan siap melakukan praktik kerja industri. Kesiapan siswa harus dikuatkan melalui peningkatan adaptasi lingkungan tempat kerja terutama dalam hal pengetahuan bidang pekerjaan dan keterampilan menggunakan peralatan di industri.

2. SMK yang menyelenggarakan program keahlian Teknik Bangunan sangat siap melakukan praktik kerja industri. Penyiapan pemahaman akademik dan keterampilan dasar teknis siswa menjadi salah satu pokok penting dalam meningkatkan kemampuan siswa dalam beradaptasi dengan lingkungan prakerin nantinya.

3. Industri pasangan prakerin siap melakukan praktik kerja industri terutama bagi industriindustri golongan besar dan menengah, sementara untuk industri golongan kecil hanya $75 \%$ yang siap melaksanakan prakerin. Keterbukaan industri dalam menerima peserta prakerin menjadi langkah awal kemitraan industri dalam mendapatkan calon tenaga kerja terampil yang siap kerja.

\section{UCAPAN TERIMA KASIH}

Kami mengucapkan terima kasih kepada DP2M Dikti Kementerian Pendidikan dan Kebudayaan melalui Lembaga Penelitian Universitas Negeri Makassar atas dukungan biaya yang diberikan. Ucapan terima kasih juga kami sampaikan kepada Tim Redaktur Cakrawala Pendidikan yang telah memberikan review dan diterbitkannya artikel ini. 


\section{DAFTAR PUSTAKA}

Becker, K. 2007. "Digital Game-Based Learning once Removed: Teaching Teachers". British Journal of Educational Technology, 38(3), 478-488

Boud, D. \& Solomon, N. 2001.Work-based Learning: A New Higher Education? Philadelphia: SRHE and Open University Press.

Fleming, J., \& Martin, A. J. 2007. "Facilitating Reflective Learning Journeys in Sport Cooperative Education". Journal of Hospitality, Sport, Tourism, Leisure and Education, 6(2), 115-121.

Pardjono \& Hestina Windiyati. 2012. "Pengembangan Model Pembelajaran Soft Skills dan Hard Skills untuk Siswa SMK". Cakrawala Pendidikan, No. 2, (2012), 336-350.

Raelin, J. A. 2008. Work Based Learning: Bridging Knowledge and Action in The Workplace. San Francisco: Jossey-Bass A Wiley Company.

Reeve \& Gallacher. 2005. Integrating WorkBased Learning into Higher Education : A guide to good practice.. Diambil pada tanggal 20 oktober 2012, dari http://www. uvac.ac.uk/downloads/0401_publications/ int_wbl .pdf
Rhodes, G. \& Shiel, G. 2007. "Meeting the Needs of the Workplace and the Learner Through Work-Based Learning". Journal of Workplace Learning, 19(3), 173-187.

Slamet PH. 2013. Pengembangan Model SMK Untuk Masa Depan. Cakrawala Pendidikan, No. 1, (2013), 14-26.

Syamhanim Ismail, Mimi Mohaffyza Mohamad, Norasyikin Omar, Yee Mei Heong, Tee Tze Kiong. 2015. "A Comparison of the Work-based Learning Models and Implementation in Training Institutions", Procedia - Social and Behavioral Sciences, Volume 204, 24 August 2015, Pages 282-289, ISSN 1877-0428, http://dx.doi. org/10.1016/j.sbspro.2015.08.153. (http:// www.sciencedirect.com/science/article/pii/ S1877042815048016)

Wardiman D. 1998. Pengembangan Sumber Daya Manusia melalui Sekolah Menengah Kejuruan (SMK). Jakarta: Jayakarta.

Widarto, Pardjono, \& Noto Widodo. 2012. "Pengembangan Model Pembelajaran Soft Skills dan Hard Skills untuk Siswa SMK". Cakrawala Pendidikan, No. 3, (2012), 409-423. 